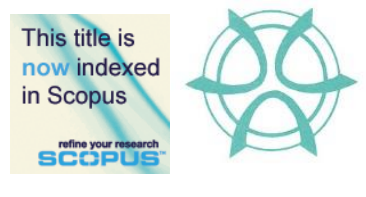

PLANNING MALAYSIA:

Journal of the Malaysian Institute of Planners

VOLUME 15 ISSUE 4 (2017), Page 91 - 104

\title{
ECO PUBLIC ART PLACEMAKING FRAMEWORK: A CASE STUDY OF LAMAN SENI SHAH ALAM, MALAYSIA
}

\author{
Khalilah Zakariya ${ }^{1}$ \& Syamim Azhari ${ }^{2}$ \\ ${ }^{1,2}$ Kulliyyah of Architecture \& Environmental Design \\ INTERNATIONAL ISLAMIC UNIVERSITY MALAYSIA
}

\begin{abstract}
The implementation of public art in the outdoor spaces has been acknowledged by various designers and researchers to enliven public spaces. The contributions of public art towards social well-being have also gained a growing attention among researchers for the past three decades. Within the recent years, efforts of placemaking have begun to be initiated by local authorities, as a way of reinforcing the sense of belonging among the public towards their public spaces. While the placemaking process is commonly adopted as a method to revive cities and communities, however, there has not yet been any documentation on the use of public art as part of the process, particularly in Malaysia. This study aims to establish the Eco Public Art Placemaking Framework to guide local authorities and built environment professionals adopt public participation in the public art process. This study has examined Laman Seni Shah Alam as a case study, which is a back lane revitalization project that has been transformed through eco public art. Through semi-structured interviews with the local authority, the organizer and the artists, this study has discovered that the framework is collaborative and multidisciplinary, and that there are four main phases in the framework. This study concludes that the framework has potential to be adopted by local authorities in Malaysia, and it can enable a more holistic process between the local government, consultants, artists and the public.
\end{abstract}

Keyword: eco public art, placemaking, back lane.

Date Received: $18^{\text {th }}$ July 2017

Date of Acceptance: $6^{\text {th }}$ November 2017 
Khalilah Zakariya, \& Syamim Azhari

Eco Public Art Placemaking Framework: A Case Study of Laman Seni Shah Alam, Malaysia

\section{INTRODUCTION}

The integration of public art in landscape architecture has been known to promote activities, values, functions and roles to the public. The discourse on the contribution of public art towards the social wellbeing of the public has gained a growing attention among landscape architects, local authorities and academicians over past three decades. This is especially relevant in promoting public participation that is in line with Local Agenda 21. The public's engagement in the execution of public art has been widely advocated as part of the placemaking process. However, in Malaysia, there is currently no existing framework that can act as a point of reference for landscape architects to adopt when engaging with public art and placemaking projects.

Furthermore, there is an escalating concern in the industry on the needs to create public space projects that are green and eco-friendly, while also improving the public's appreciation and awareness of the environment. To achieve this, the implementation of Eco Public Art as an approach to transform underutilized public spaces has been widely implemented in many countries, such as America, Australia, China, Japan, Singapore, and including Malaysia. Recent studies and revitalization projects prove that revitalizing underutilized public spaces, such as the back lanes, has contributed to the increase in public space comfort, engaging provisions for pedestrians within the urban core, functioning as the green lungs to the city, functioning as flexible spaces, and increasing the publics' environmental awareness (Mohd Tawil et al., 2013; Lorinc, 2014; Fialko $\&$ Hampton, 2013). The engagement of the public in Eco Public Art is part of the Placemaking Process. While Placemaking Process is common in the development of community spaces, however, there has not yet been documentation on the "Eco Public Art Placemaking Framework" in particular. The absence of this framework in current Malaysian landscape architecture industry poses a challenge for the public and private practitioners to adopt the public participation process for public art.

The aim of this study is to establish the Eco Public Art Placemaking Framework to guide local authorities and landscape architects adopt public participation in the public art process, in line with Local Agenda 21. This study has examined Laman Seni Shah Alam as a case study, which is a back lane revitalization project that has been transformed through Eco Public Art. The objectives are: (1) To identify and document the Eco Public Art Placemaking Process and the roles of landscape architects, local authority, artists and the public; (2) To examine the Eco Public Art Attributes that can guide the implementation of other Eco Public Art in different context; and (3) To propose the "Eco Public Art Framework" that can be referred and adopted by local authorities and consultants. 


\section{RESEARCH BACKGROUND}

The introduction of public art as an approach of back lane transformation has been widely implemented in many countries and cities such as America, Australia, China, Japan, Singapore and Malaysia. Recent studies and revitalization projects found that back lane revitalization has contributed to the increase of comfort in public spaces, enhance engagement of pedestrians within the urban core, contribute to the green lungs of the city and can function as flexible spaces (Mohd Tawil et al., 2013; Lorinc 2014; Fialko \& Hampton 2013). The newly activated back lanes also offer better connections between larger public hubs, and have enhanced the character of the city by serving as lively, dense, and human-scale spaces. Recently, the public's engagement in the execution of public art has been widely conducted as part of the placemaking process. While the increasing community engagement can be viewed as a means of achieving improved outcomes, placemaking is a process with the approach of 'revitalizing, planning, designing and managing the public space' (Greenspace Scotland, 2015). In this case, placemaking process is not just the act of building or fixing up a space, but it fosters the creation of public places where people feel a strong sense of connection to their surroundings.

Public art indeed plays an important role in contributing to enhance and develop the character and identity of an area (Weber, 2003). Not only because of its aesthetic value that attracts people, but it also helps to create the sense of place (Hall \& Robertson, 2001; Sucher, 1995), which means the particular experience of a person in particular setting (Steele, 1981). On the other hand, Hall and Robertson (2011) claim that public art contributes to the development of a sense of community, civic identity, addressing community needs, tackling the social exclusion, promoting the educational value and promoting the social change. Thus, public art is not just a matter of an artwork sited in public space. Public art is an art that aims to create spaces, which also engages with its audience and community of an area.

While the urban development and community's needs are sometimes not in parallel, public art bridges these two. Looking to the positive side of it and realizing the great contribution of public art and potential of back lanes, recently, many countries have put an effort to implement the use of public art as part of their back lane revitalization strategy.

The public art programme is aligned with the placemaking concept, which focuses on planning, designing and managing the public space for the community. The concept of placemaking has been studied extensively across multiple discipline. "Placemaking" is an idea derived originally from Jane Jacobs in the 1960's and William H. Whyte in the 1980's. Both of these urban researchers studied on how people interact with space (Jacobs, 1961; Whyte, 1980). Rather than merely focusing on developing space in urban planning, they instead look at the users that inhabit that place. Placemaking lies between the 
Khalilah Zakariya, \& Syamim Azhari

Eco Public Art Placemaking Framework: A Case Study of Laman Seni Shah Alam, Malaysia

concepts of transforming space into a place and the roles of community in participatory processes for future urban planning. The community here, refers to a geographical region, such as neighbourhood, town or city. On the other hand placemaking can be defined as the act or process of creating great places with an emotional connection with its users. It is how we construct and connect to our surroundings, the way we build the communities, and build the relationship with the people in an area. While there is no agreed definition of placemaking, it is generally understood as a process that is part of urban design that makes places liveable and meaningful (Flemming, 2007).

Recent studies have proven that placing public art in public space can enhance user experience and enliven spaces. Developing the public art plan encompasses public art committee who is the key player to shape the whole plan, set up the vision, mission, goals, finding source of funding, selection of location, artist, to look into the relevant regulations and what are the benefits to the community (Schneekloth \& Shibley, 1995). The public art programme is an effort of creating continuous experiences that shape the community by developing the sense of place, articulate the aesthetic values of the public art itself in order to create a desirable place to live, work and play. The public art programme and placemaking process have the same goals and share the same process of shaping and designing public space, through building up the community and the place (Martin 2001; Zukin, 1995). While placemaking is a process, public art acts as the additional attraction elements in it. It is also part of the practice of placemaking.

\section{METHODS}

A qualitative method was used for this study through a case study approach, where the site selected is Laman Seni 7 in Shah Alam, Selangor. Laman Seni 7 is a back lane revitalization project that implements the use of public art as part of its placemaking approach. Semi-structured interviews were conducted with six purposefully selected respondents based on their expertise. In order to get a deeper understanding of the process, the interviews were conducted with two of Shah Alam City Council Officers, Principal and Public Relations (PR) person of KHZNH.Studio, and two of the artists involved in the Laman Seni 7 project. Located at the commercial urban area in Section 7 Shah Alam, the Laman Seni 7 is a continuous project of Laman Seni Section 2 that was initiated by Shah Alam City Council (SACC) in collaboration with KHZNH.Studio, aiming to transform the back lanes to be the focal point for the youth to utilise. The transformation of Laman Seni 7 was done through a competition as an effort to engage the public to together involve in this project. It is said to act as a platform for the younger generations, especially the students, to explore their talents and fresh ideas. 
The aim of the interview was to find out the initial ideas and procedures involved in revitalizing the back lane and public art for Laman Seni 7 from three (3) different point of views: the Local Authority (SACC), the Organizer (KHZNH.Studio) and the Artists as public participants. Three sets of interview questions were developed based on each of their expertise. However, the main points for each interview are similar according to the process involved.

\section{FINDINGS AND DISCUSSION}

From the interviews, the first distinction that can be made between the different parties involved throughout the public art placemaking process were phases and process involved. There were four main phases, which were: 1) Planning stage; 2) Designing stage; 3) Executing and implementing stage; and 4) Maintenance and programming stage. Each of these phases had to undergo the detailed procedure and had to follow the timeline as outlined during the early planning stage. Each phase also incorporated collaborations between other parties, who were from the local authority, the organizer, the artist and the public. SACC represented the local authority, KHZNH.Studio represented the organizer, while the artists were selected based on a competition held. Respectively, each of them had their own tasks to be completed, managed or delegated. Their roles were in line with their expertise in order to make sure the actions taken by them followed the initial planning and timeline made for the project to complete. Based on the analysis of the interview data as informed by each respondent, the phases involved in the eco public art placemaking process is illustrated in Figure 1. 
Khalilah Zakariya, \& Syamim Azhari

Eco Public Art Placemaking Framework: A Case Study of Laman Seni Shah Alam, Malaysia

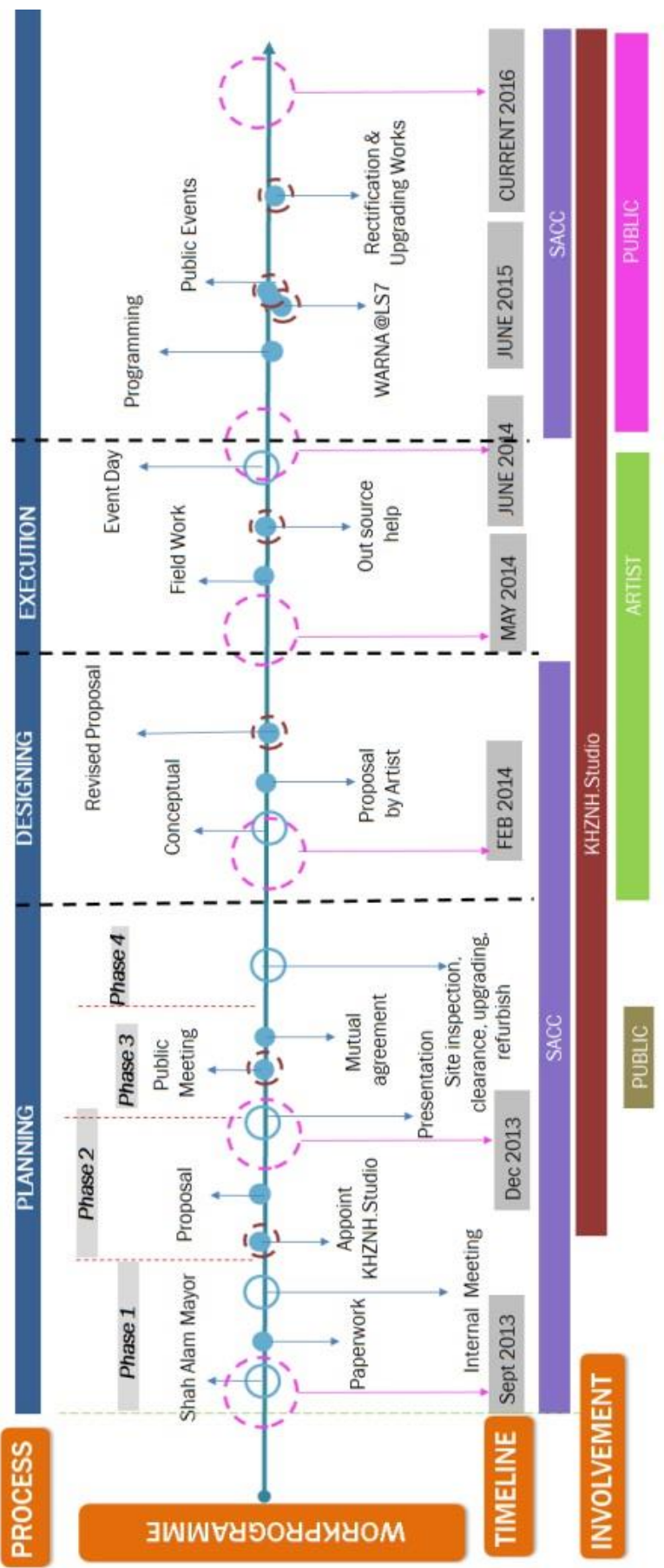

Figure 1 Public art placemaking process for Laman Seni 7 
PLANNING MALAYSIA

Journal of the Malaysia Institute of Planners (2017)

\section{Roles of the Local Authority}

Literature review shows that public art placemaking in Washington D.C. involves the Public Art Placemaking Commission Board (PAPCB), which is a team under the local authority that is led by the Mayor to run and evaluate actions on matters with regards to the arts and encourage any arts programme for the benefit of a city and the community (D.C Public Art Master Plan, 2009). PAPCB is responsible to appoint members of the Public Art Placemaking Committee (PAPC). PAPC shall consist of people with different expertise, backgrounds and skills, not necessarily to be from the city council members. They are responsible to advise the local authority in carrying out the placemaking process, dealing with the public and community, recommend appropriate locations for the project, and oversees the commissioning of artwork, maintenance programs, annual programs and also events to be held. However, for this case study, a different approach was used.

The SACC were both the PAPCB and PAPC themselves. They were the main key players in placemaking project for Laman Seni 7, and responsible for the initial ideas and planning until the execution and post-execution phase. According to Respondent LA1:

\footnotetext{
"We are appointed by the Higher Management of SACC (PACB) as the Secretariat for Laman Seni 7 revitalization project. As the Secretariat for this project, our duty starts from preparing the paperwork, the best strategy, funding and budget, liaise with the internal support system of SACC which are the technical team from various departments, monitoring the execution and action plan, also as the middle man between SACC and the organizer." (LA1, public relations officer, March 25, 2015).
}

Ultimately, the SACC were responsible for the whole programme of revitalizing the Laman Seni 7 back lane project, especially on the planning details, annual programmes, funding, and the selection of location, including the laws and regulations that need to be followed. At this stage, the local authority played an important role in the overall two years planning for Laman Seni 7. In addition, particularly for this project, three divisions in SACC were involved. They were the Higher Management led by Shah Alam Mayor or also known as the PAPCB; the Public Art Placemaking Prelim Consultant (PAPPC) which was the technical supporting system consisting of architects, landscape architects, planner, engineers, lawyers; and the PAPC, which the members were from the Corporate Department of SACC. Each team had different roles and responsibilities. All of the action plans or programmes proposed and done by the corporate department as the PAPC must get the approval from the Mayor prior to any decisions and actions taken.

The corporate department were responsible for the proposal preparation phase until the action plan was executed. Not only that, they were also responsible 
Khalilah Zakariya, \& Syamim Azhari

Eco Public Art Placemaking Framework: A Case Study of Laman Seni Shah Alam, Malaysia

for the programming stage, which was during the post-execution of the public art stage. Their scope of work began from preparing the proposal to be presented to the mayor, planning the annual public art placemaking work plan, community programmes, liaising with a few other parties, and the artist selection. The Public Art Placemaking Prelim Consultant (PAPPC) was the technical team from the technical department responsible in giving advices based on their expertise. These departments comprised the Building Department, Development Department, License Department, Enforcement Department, Engineering Department, Landscape Department and Solid Waste Department. Their advises included giving ideas and comments on any proposal done by the corporate department, laws and regulations related to developing back lanes, the site upgrading process, solid and waste issues, and involved in site visits and clearance stage.

\section{Role of the Organizer}

The Public Art Placemaking Action Team (PAPAT) is appointed by PAPC with the approval form PAPCB to act as the 'middle man' in developing a collaborative relationship between the public and local authority. KHZNH.Studio was appointed by SACC based on their previous experience as the organizer for the Laman Seni 2 project. Hence, they have had series of experience in handling similar projects, which made it easier for SACC to work with. KHZNH.Studio was responsible for the process of selecting the artist, preparing proposal for any public programmes at Laman Seni, and carrying out the publicity and promotions. Not only that, they were accountable to make sure all programmes that have been approved are done accordingly. Furthermore, the organizer was also liable in conducting workshops to present the ideas of back lanes revitalization for Laman Seni 7 to the shop owner and operators as part of the public engagement. Basically, as the PAPAT, they were involved in most of the phases throughout the Laman Seni 7 Backlane Revitalization programme. According to Respondent OR1:

\footnotetext{
"We are involved in the planning process from updating a detail proposal for public art programmes including the concepts, themes, the types and illustration to be presented to the Mayor to get his approvals". (OR1, principle of KHZNH.Studio, February 18, 2015)
}

The organizer took the leading role in coordinating the project to meet both the needs of the local authority, the artists and the public. For Laman Seni 7, the organizer was a group composed of individuals with multidisciplinary architectural-based background that focuses on solving community-related issues through architecture, design and public engagements. Their role in this project as the organizer can be adopted by other design consultants or organizations that intend to conduct a public art placemaking project. 
PLANNING MALAYSIA

Journal of the Malaysia Institute of Planners (2017)

\title{
Role of the Artist
}

For Laman Seni 7, the selection of artists was done through a competition that was held for about two months before the installation of public art at the site. It was an open competition, whereby artists from all over Malaysia need to submit their first draft proposals according to the themes that have been determined by both the Placemaking Committees and Action Team. There are a total of four categories and three themes to be followed. At this stage, both Placemaking Committees and the Action Team were also the review panels for artist selections. As informed by Respondent AR2:

\begin{abstract}
"We heard about the LS 7 competition from a mutual friend who accidentally found the competition page on Facebook. So when the opportunity presented itself we didn't think twice in participating. Because as a designer, we felt it was the perfect medium for us to express our creativity and talent. So we decided to enter three of the four categories available." (AR2, Architect, April 16, 2015)
\end{abstract}

After the first round of qualifications and requirements reviewed by the selection panels, several of the artists were shortlisted to submit their final proposals for the second stage. For Laman Seni 7, 40 artists were shortlisted, where ten artists submitted for each category. The shortlisted artists were given about one month to execute and install their artworks. A workshop between the artists, Placemaking Committee and Action Team was held to do the final review of their submitted final proposals. This was the stage where some of their artwork needed to be changed in accordance with the laws, guidelines and also several factors such as the theme, the colour selection and the materials. During the execution phase, some of the artists outsourced specialized works to other experts in order to make sure their installations can produce great artworks similar to their proposals.

Table 1 summarizes the roles of the local authority, organizer and the artists in the public art place making process.

Table 1 Roles in public art placemaking process for Laman Seni 7

\begin{tabular}{ll}
\hline \multicolumn{1}{c}{ Organization } & \multicolumn{1}{c}{ Roles } \\
\hline \multicolumn{1}{c}{ Local Authority } & : Shah Alam City Council (SACC) \\
\hline a. Public Art Placemaking & - Initiate PAPP ideas \\
Commissions Board (PAPCB) & -Approve PAPP action plan / annual plan \\
& /yearly plan \\
-Higher Management Team & -Approve budget and funding \\
& - Appoint member of PAPC and PAPPC \\
b. Public Art Placemaking Prelim & - Advise on technical issues \\
Consultant Team (PAPPC) & - Involve in site clearance, upgrading and \\
& maintenance works
\end{tabular}


Khalilah Zakariya, \& Syamim Azhari

Eco Public Art Placemaking Framework: A Case Study of Laman Seni Shah Alam, Malaysia

- Review and approve the technical proposal and actions prior to Mayor's approval

c. Public Art Placemaking - Prepare the proposal, annual plan, Committee (PAPC) documentation -Outline goals, policies, and procedures -Involves in selecting the artist

- Programs / Publicities -Identify collaboration and source of fund

\begin{tabular}{cl}
\hline \multicolumn{2}{c}{ Non-Government Organisation (NGO): Khznh.Studio } \\
\hline a. Public Art Placemaking Action & - Appointed by PAPC \\
Team (PAPAT) & - Oversees the public art installations and \\
& programs \\
& - Publicity / social network /media \\
& - Handling workshops \\
& - Liaise with local authority and public \\
& -The event's organizer /planner \\
& -Other works required by SACC \\
\hline Artist & \\
\hline a. Public Art: The makers & - Initiate artwork ideas \\
& -Artworks Installation \& Execution \\
\hline
\end{tabular}

\section{RECOMMENDATION AND CONCLUSION}

The eco public art placemaking process is a collaborative and multidisciplinary process. There are many factors to take into account in order to achieve the main goal of creating a meaningful and useful place that benefits the community. Based on the findings of this study, what can be concluded is the importance of having a good collaboration and a great team throughout the whole process. Despite the different backgrounds and scope of work of each committee involved in the Laman Seni 7 back lane revitalization project, they had actually managed to work together to ensure the completion of the public art meets the objectives and timeline of the project. A thorough understanding of the different roles and high commitment by each of these parties is one of the factors that need to be coordinated. Mapping this process is important in order to produce a comprehensive and a detailed operational document for the eco public art placemaking process. Furthermore, this process can be used as a reference in any public space projects that involves public art in future.

This study recommends the Eco Public Art Placemaking Framework, as illustrated in Figure 2. 
Journal of the Malaysia Institute of Planners (2017)

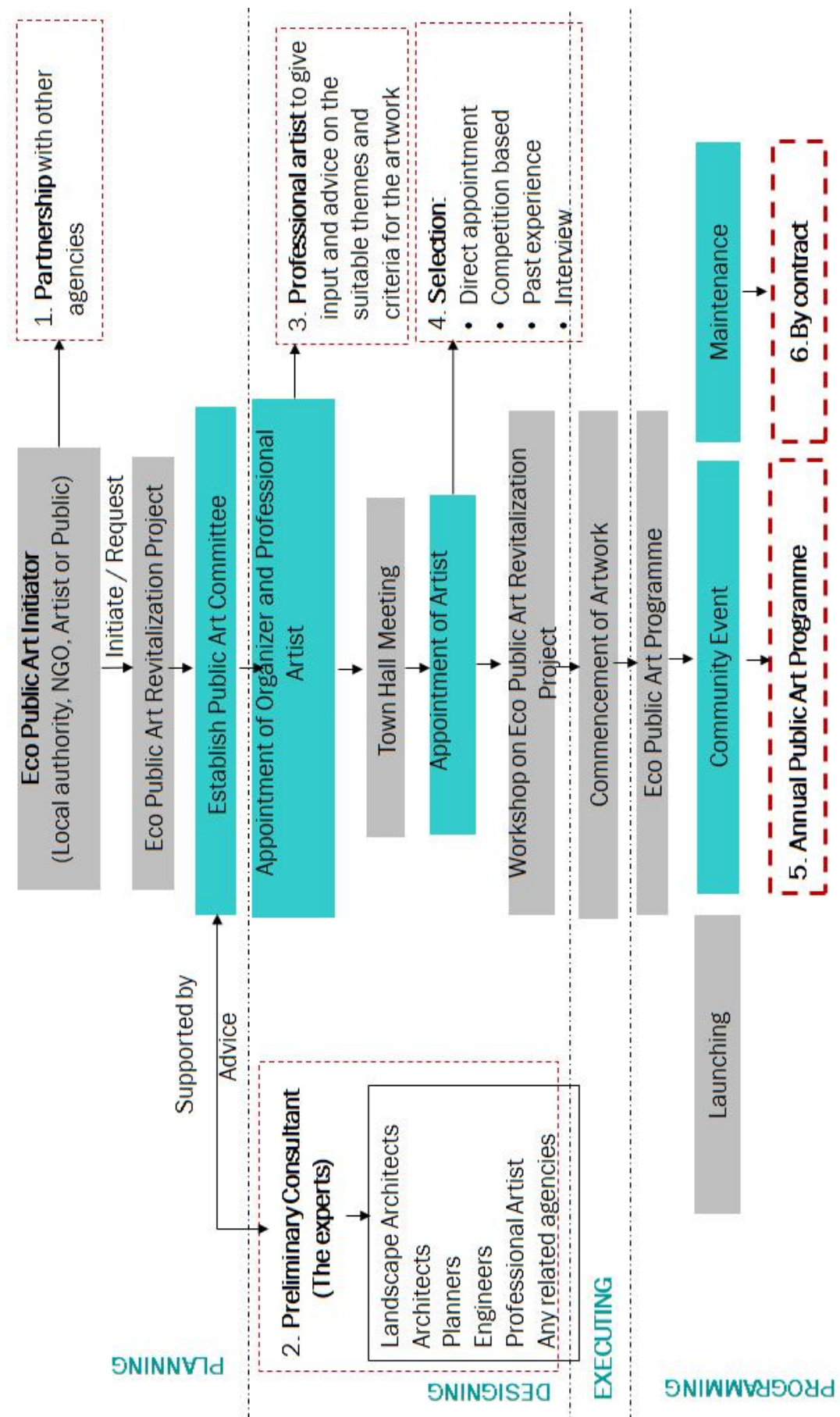

Figure 2 Eco Public Art Placemaking Framework 
Khalilah Zakariya, \& Syamim Azhari

Eco Public Art Placemaking Framework: A Case Study of Laman Seni Shah Alam, Malaysia

This study has discovered several key findings. First, the Eco Public Art Placemaking Framework is a collaborative and multidisciplinary framework that can be adopted by local authorities, consultants, developers and the community in incorporating public participation in public art. The execution of public art should include representatives from the public, and this is in line with Local Agenda 21 in ensuring public spaces meet the needs of the community. The framework is not limited to public art in the back lanes, but rather can be adopted by any public art projects. Second, the identification of the Eco Public Art Placemaking Framework can guide other local authorities to plan and implement public art as part of their public space revitalization initiative. The implementation of the public art in public spaces also helps to revitalize underutilized spaces as functional spaces for public use. This study concludes that the framework has potential to be adopted by local authorities in Malaysia, and it can enable a more collaborative process between the local government, consultants, artists and the public.

\section{ACKNOWLEDGEMENTS}

This study was funded by the MyRA Incentive Research Grant Scheme from the Ministry of Higher Education Malaysia. The findings in this study were previously presented at the $4^{\text {th }}$ International Conference of Applied and Creative Arts in 2015. 


\section{REFERENCES}

Greenspace Scotland (2015). Community placemaking. Retrieved July $8^{\text {th }} 2015$ from http://greenspacescotland.org.uk/ outcomes-planning-and-evaluation.aspx.

Fialko, M., \& Hampton, J. (2013). Activating alleys for a lively city. Seattle, Washington: Integrated Alley Handbook

Flemming, R. L. (2007). The art of placemaking. New York: Merrel.

Hall, T., \& Robertson, I. (2001). Public art and urban regeneration: Advocacy, claims and critical debates. Landscape Research, 26(1), 5-26.

Jacob, J. (1961). The death and life of great American cities. New York: Random House.

Lorinc, J. (2014). From garbage to greenery: revitalizing Toronto's downtown laneways. The Globe and Mail. Retrieved from https://beta.theglobeandmail.com/news/toronto/from-garbage-to-greeneryrevitalizing-torontos-downtownlaneways/article1358493/?ref=http://www.theglobeandmail.com\&

Mohd Tawil, N., Md Lias, S. F., Usman, I. M. S., \& Kosman, K. A. (2013). Evolution of back lane design: A view of terrace housing in Malaysia. Asian Social Science, 9(15), 277-288.

Martin, M. D. (2001). The question of alleys, revisited. URBAN DESIGN International, 6(2), 76-92.

Schneekloth, L. \& Shibley, R. (1995). Placemaking: the art and practice of building communities. New York: John Wiley \& Sons, Inc.

Steele, F. (1981). The sense of place. Boston, Massachusetts: CBI Publishing Company, Inc.

Sucher, D. (1995). City comforts: How to build an urban village. Seattle: City Comforts Inc.

Weber, J. P. (2003). Politics and practice of community public art: Whose murals get saved? California: The Getty Conservation Institute.

Whyte, W. H. (1980). The Social Life of Small Urban Spaces. New York: Conservation Foundation.

Zukin, S. (1995). The cultures of cities. United Kingdom: Blackwell Publishers. 
Khalilah Zakariya, \& Syamim Azhari

Eco Public Art Placemaking Framework: A Case Study of Laman Seni Shah Alam, Malaysia

This page intentionally left blank 